\title{
Comparison of HF and HCl Chemical Laser Parameters by using Mathematical Model
}

\author{
Rafah Abdul Hadi *
}

Date of acceptance 17/1/2007

\begin{abstract}
:
A simplified theoretical comparison of the hydrogen chloride $(\mathrm{HCl})$ and hydrogen fluoride (HF) chemical lasers is presented by using computer program. The program is able to predict quantitative variations of the laser characteristics as a function of rotational and vibrational quantum number. Lasing is assumed to occur in a Fabry-Perot cavity on vibration-rotation transitions between two vibrational levels of hypothetical diatomic molecule. This study include a comprehensive parametric analysis that indicates that the large rotational constant of $\mathrm{HF}$ laser in comparison with $\mathrm{HCl}$ laser makes it relatively easy to satisfy the partial inversion criterion. The results of this computer program proved their credibility when compared with the little published data.
\end{abstract}

\section{Introduction:}

Although the first chemical laser was an $\mathrm{HCl}$ laser reported by Kasper and Pimental (1965), the $\mathrm{HCl}$ laser has received relatively little attention. Investigations on chemical fluorine + hydrogen chain-reaction lasers peaked in 1970s and 1980s, meanwhile the chain chemical reaction is now more studied than the conventional oxygenhydrogen one (Bravy,1996). The use of the hydrogen fluorination chain reaction chain reaction for which the rate of the chain chemical pumping process is much higher than that of deactivation processes has helped to make certain progress in this direction is that the number of vibrationally excited molecules produced in its course is much greater than that of the priming atoms formed during initiation (Basov and et al,1990).

To compare $\mathrm{H}_{2}+\mathrm{Cl}_{2}$ with the $\mathrm{H}_{2}+\mathrm{F}_{2}$ chain reaction chemical systems. The combination of: (i) IR spectral range suitable for molecular vibrations attack as well as for transmittance in atmosphere, (ii) large number of lines, and (iii) high peak power, makes $\mathrm{HCl}$ laser very promising tool (Gordon and et al, 1997). But its short coming, in comparison with HF laser, was a low efficiency, arising from the absence in $\mathrm{H}_{2}+\mathrm{Cl}_{2}$ system of fast chain reaction inherent to $\mathrm{H}_{2}+\mathrm{F}_{2}$ one. The $\mathrm{HF}$ pulsed chemical laser on a chain $\mathrm{H}_{2}+\mathrm{F}_{2}$ are indisputable leader among the pulsed lasers. The chemical reaction is initiated for example by $\mathrm{F}$ atoms photolytical formation $\mathrm{F}_{2}+\mathrm{h} v \rightarrow 2 \mathrm{~F}$, followed by fast chain reaction. The reaction of $\mathrm{H}_{2}$ and $\mathrm{F}_{2}$ to form excited $\mathrm{HF}$ takes place in two steps: the "cold reaction":

$$
\mathrm{F}+\mathrm{H}_{2} \rightarrow \mathrm{HF}^{*}+\mathrm{H} \quad \Delta \mathrm{H}=-134 \mathrm{~kJ} / \mathrm{mole} \quad \ldots \text { (1) }
$$

And the "hot reaction":

$$
\mathrm{H}+\mathrm{F}_{2} \rightarrow \mathrm{HF}^{*}+\mathrm{F} \quad \Delta \mathrm{H}=-406 \mathrm{~kJ} / \text { mole } \ldots(2)
$$

where vibrationally excited $\mathrm{HF}^{*}$, molecules appear in both links of the chain. 
Since the hot reaction releases more energy and populates higher vibrational bands of HF than the cold reaction, there has been considerable interest in utilization of the hot reaction to increase laser power (Detweiler and Sentman, 2005).

The above reaction (1) known as pumping reaction, of fluorine (oxidizer) and hydrogen (fuel) produces about $14.7 \mathrm{~kJ} / \mathrm{g}$ of fluorine with approximately $60 \%$ of the energy going into excited vibrational states of HF molecule (Wisniewski, 2003). This energy distribution allows for the creation of population inversion required for lasing. Excited state of HF can be deactivated by collision with other species inside laser cavity at rates as fast as the pumping reaction. Due to this, the fuel and oxidizer are kept separately until they reach the optical cavity (Palekar, 2004).

In most respects $\mathrm{HF}$ and $\mathrm{HCl}$ are quite similar; the main difference in the chemistry of the two systems lies in the lower bond energy of $\mathrm{HCl}(4.43 \mathrm{eV})$ while the HF bond energy (5.86 eV) (Eletskii, 1981).resulting generally in lower reaction exothermicities for $\mathrm{HCl}$ - forming reactions. In particular, in the $\mathrm{H}_{2}-\mathrm{Cl}_{2}$ chain reaction, only the reaction

$\mathrm{H}+\mathrm{Cl}_{2} \rightarrow \mathrm{HCl}^{*}+\mathrm{Cl} \quad \Delta \mathrm{H}=-189 \mathrm{~kJ} /$ mole $\ldots$ (3)

leads to vibrational excitation. The reaction

$\mathrm{Cl}+\mathrm{H}_{2} \rightarrow \mathrm{HCl}^{*}+\mathrm{Cl} \quad \Delta \mathrm{H}=+4 \mathrm{~kJ} /$ mole $\ldots$ (4)

produces only $\mathrm{HCl}$ in the ground state. Thus, although the $\mathrm{H}_{2}+\mathrm{Cl}_{2}$ chain reaction has been used for flash lamp pumped $\mathrm{HCl}$ lasers, the system is inherently inefficient (Stitch, 1979).

It can be shown that $\mathrm{HCl}$ molecules appear in the zero vibrational state $\left(\mathrm{E}_{0}=0\right)$ in the reaction (4), and only
$0.015 \%$ of the $\mathrm{HCl}$ molecules formed occupy the $\mathrm{v}=6$ level corresponding to an energy of $189 \mathrm{~kJ} / \mathrm{mole}$.The small fraction of $\mathrm{HCl}$ molecules carrying away a large amount of vibrational energy at the moment of their formation, as well as the high probability of vibrational and rotational energy dissipation by molecular collisions.

Things are different for a similar reaction between fluorine and hydrogen (reaction 2), where the heat of reaction is 2.5 times higher than the endothermicity of the fluorine molecule dissociation. Thus it may be assumed that the number of excited HF molecules with energy sufficient to dissociate $F_{2}$ on collision will be considerably higher than in the case of $\mathrm{HCl}$.

Chemical lasers have many attractive features, they produce the highest output power per unite volume and per unite weight. In general, chemical reactions excite vibrational levels and thus the output wavelength is always in the infrared ( $1 \mu \mathrm{m}$ to $12 \mu \mathrm{m}$ ). If one - shot large power is needed as, for example, in a star wars scenario, chemical lasers can produce large amounts of destructive energy without any electrical power (Das, 1991).

In the present work, theoretical studies of $\mathrm{HF}$ and $\mathrm{HCl}$ chemical lasers were performed in order to determine the effect of some parameters in the laser production.

\section{Model Formulation}

Formulation of the chemical laser model using Matlab computer programs, laser vibration-rotation state populations $\mathrm{N}(\mathrm{v}, \mathrm{J})$ are computed from the kinetic reactions, with the effect of lasing, absorption, and spontaneous emission taken into account. The gain coefficient is $\alpha(v, J)=\frac{h N_{A}}{4 \pi} \omega_{c}(v, J) \phi_{c} B(v, J) \times\left[\frac{g_{l}}{g_{u}} n_{v}-n_{l}\right] \ldots(5)$ 
where $\mathrm{v}$ and $\mathrm{J}$ are quantum numbers of the transition's lower level, $\mathrm{h}$ is Planck's constant, and $\mathrm{N}_{\mathrm{A}}$ is the Avogadro's number. $\omega_{\mathrm{c}}(\mathrm{v}, \mathrm{J})$ is the wave number of the transition, $\mathrm{B}(\mathrm{v}, \mathrm{J})$ is an Einstein coefficient, $g_{u}$ and $g_{1}$ are upper and lower state degeneracies. The wave number for P-branch transition into level $(\mathrm{v}, \mathrm{J})$ is taken as Kerber and Whittier (1976),

$$
\omega_{\mathrm{c}}(\mathrm{v}, \mathrm{J})=\omega_{\mathrm{v}}-(2 * \mathrm{~J} / 1.4388) * \theta_{\mathrm{r}}(\mathrm{v}) \ldots(6)
$$

where $\mathrm{v}=0,1,2,3 \ldots \ldots$ And $\mathrm{J}=1,2$, $3 \ldots . . \quad \theta_{\mathrm{r}}(\mathrm{v})$ is the characteristic rotational temperature which is approximated by $\theta_{\mathrm{r}}(\mathrm{v})=(30-\mathrm{v})$ kelvin, and the constant 1.4388 is hc/k (where $\mathrm{h}$ is Planck's constant, c is speed of light and $\mathrm{k}$ is Boltzman constant).

Both Doppler and pressure broadening are considered through use of the Voigt profile $\phi_{c}$, evaluated at line center is given by

$$
\phi_{\mathrm{c}}=\left(1.0921 * 10^{6} / \omega_{\mathrm{c}}\right)(\mathrm{W} / \mathrm{T})^{1 / 2}
$$

where $\mathrm{W}$ is the molecular weight of the diatomic molecule(for $\mathrm{HF}=20 \mathrm{~g} / \mathrm{mole}$ and for $\mathrm{HCl}=36 \mathrm{~g} / \mathrm{mole}$ ) the constant $1.0921 * 10^{6}$ is $\left[\mathrm{c}^{2} \ln 2 /\left(2 \pi * 10^{7} \mathrm{~N}_{\mathrm{A}} \mathrm{k}\right)\right] 1 / 2, \mathrm{~T}$ is the absolute temperature, $\mathrm{c}$ is the speed of light, , and $\mathrm{k}$ is the Boltzmann constant. The Einstein isotropic absorption coefficient given by

$$
\mathrm{B}(\mathrm{v}, \mathrm{J})=6.282 * 10^{50}(\mathrm{~J} / 2 \mathrm{~J}+1)\left|\mathrm{M}_{\mathrm{v}+1, \mathrm{v}}\right|^{2}
$$

where $\mathrm{M}=$ the matrix element of the electric dipole moment, and

$\mid \mathrm{M}_{\mathrm{v}+1, \mathrm{v}}=(\mathrm{v}+1)^{1 / 2} *\left[\left(0.988 * 10^{-19 *}\left(1+2.66 * 10^{-2} \mathrm{~J}\right)\right] \ldots(9)\right.$

The rotational partition function where calculated taking into account the approximations that had been put forward by Kerber and Whittier (1975), the rotational temperature $\theta_{\mathrm{r}}(\mathrm{v})$ in kelvin has been computed as a function of the vibrational quantum number $\mathrm{v}$ with the aid of the following relation (as given above),

$$
\theta_{\mathrm{r}}(\mathrm{v})=30-\mathrm{v} \ldots(10)
$$

The results of the calculated $\theta_{\mathrm{r}}$ have been applied in the computations of the rotational partition function $\mathrm{Q}_{\mathrm{r}}(\mathrm{v})$. For the vibrational level $\mathrm{v}, \mathrm{Q}_{\mathrm{r}}$ may be computed from the following formula (Emanuel 1971),

$$
\mathrm{Q}_{\mathrm{r}}=\frac{1}{\sigma}\left(\frac{\mathrm{T}}{\theta_{\mathrm{r}}}\right)
$$

where $\mathrm{T}$ is the absolute temperature in kelvin and $\sigma$ is a symmetry factor; it equals to 1 for heteronuclear and 2 for homonuclear molecules.

The $\mathrm{HF}$ and $\mathrm{HCl}$ lasers action were assumed operating from three vibrationally excited levels on single vibrational-rotational transition having maximum gain coefficient for each pair of levels. The rotational distributions within a vibrational level were assumed to be in thermal equilibrium. Maximum gain vibrational-rotational transition always lies within the P-branch and its rotational quantum number may change in time being dependent on gas mixture temperature.

\section{Results and Discussion}

The certain Mathlab computer model was developed to simulate some parameters of the $\mathrm{HF}$ and $\mathrm{HCl}$ chemical lasers. The model can overpredicted performance of the chain reaction in both types of lasers. These parameters were calculated by using computer modeling. Based on the values of $\left(\omega_{\mathrm{v}}\right)$ which were given for both $\mathrm{HF}$ and $\mathrm{HCl}$ of the band energy level spacing, the wave number $(\omega \mathrm{v}, \mathrm{J})$ in $\mathrm{cm}^{-1}$ for P-branch has been calculated using equation (6) and the results plotted in Figure (1) as a function of rotational quantum number $(\mathrm{J})$ for both $\mathrm{HF}$ and $\mathrm{HCl}$ lasers. As it appears, the increases in $\mathrm{J}$ will cause a linear decrease in $\omega$ 
with a negative slope. It can be seen from the figure that the decreases in wave number with $J$ for $\mathrm{HF}$ is more clearly than for $\mathrm{HCl}$, this probably due the higher value of the band origin of $\mathrm{HCl}$ in comparison with $\mathrm{HF}$.

Figure (2) shows the variation of the matrix element dipole moment (MEDM) denoted byl $\mathrm{M}_{\mathrm{v}+1, \mathrm{v}} \mid$ at various rotational quantum numbers for both $\mathrm{HF}$ and $\mathrm{HCl}$ lasers. It is seen that MEDM increases with increasing in $J$ particularly at higher values of $\mathrm{J}$. At $\mathrm{J}=0$, the matrix element dipole moment has a certain value, as one would except from Equation (9). This linear variation of $\mathbf{M}_{\mathrm{v}+1, \mathrm{v}}$ with $\mathbf{J}$ is identical to that published by Emanuel (1971) for HF laser. The highest values of MEDM for $\mathrm{HCl}$ are due to the large values of the constants that make it relatively easy to satisfy the partial inversion criterion. However, it can be seen that the increases of MEDM with $\mathrm{J}$ is faster than that for $\mathrm{HCl}$. As a result of that, the HF laser is experimentally one of the easiest systems to get going.

Figure (3) shows the variation of rotational partition function $\left(\mathrm{Q}_{\mathrm{r}}\right)$ as a function of the temperature at three vibrational states of transition for both $\mathrm{HF}$ and $\mathrm{HCl}$. These plots are in agreement with those published by Emanuel (1971). It is seen that $Q_{r}$ increases with increasing temperature and $\mathrm{v}$, particularly at high temperatures and the values for the three states of $\mathrm{v}$ are nearly the same for HF. However, within room temperature, $Q_{r}=10$ for $\mathrm{HF}$ and for $\mathrm{HCl}$ are independent of $\mathrm{v}$ and it has different values for different $\mathrm{v}$

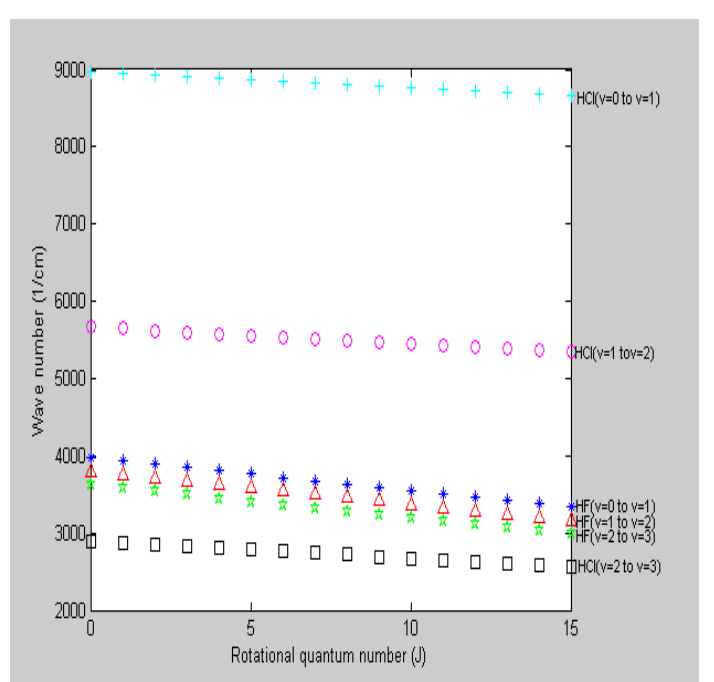

Figure (1) Wave number for $\mathrm{HF}$ and $\mathrm{HCl}$ molecules as a function of rotational quantum number $(\mathrm{J})$

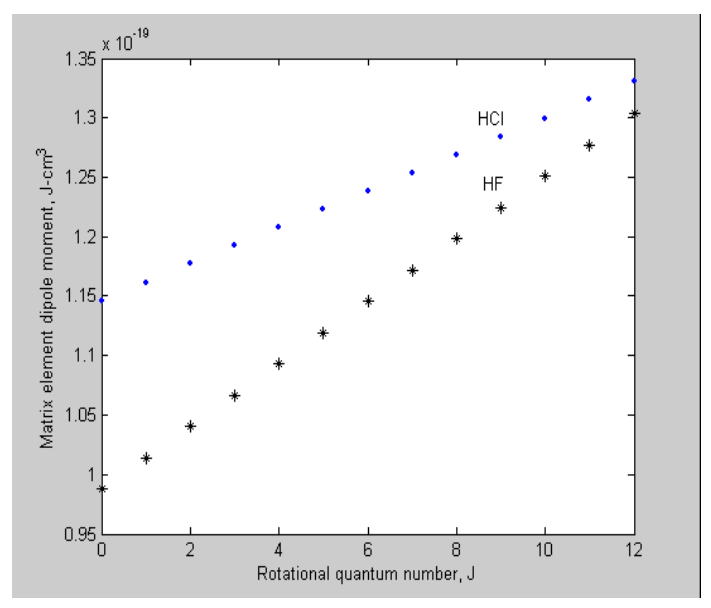

Figure (2) Matrix element dipole moment of $\mathrm{HF}$ and $\mathrm{HCl}$ molecules as a function of rotational quantum number $(\mathrm{J})$

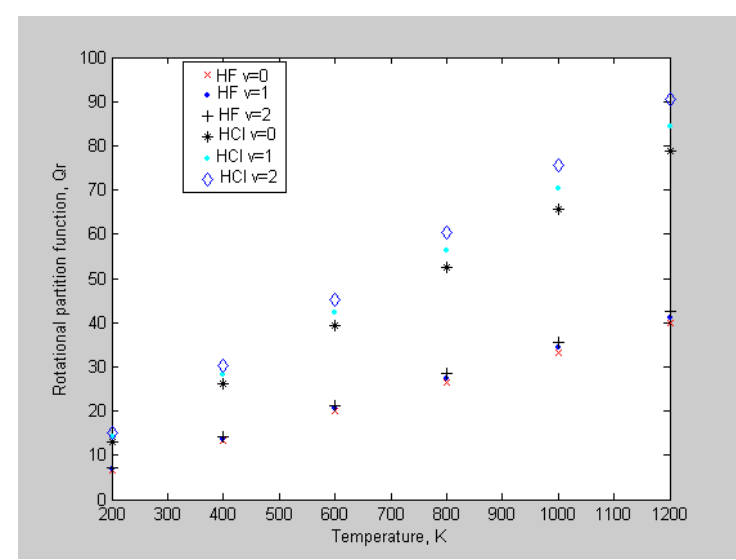

Figure (3) Rotational partition function for $\mathrm{HFand} \mathrm{HCl}$ as a function of temperature at various values of the vibrational quantum number $\mathrm{v}$. 


\section{CONCLUSION:}

In this study is presented a model by which the laser parameters pulsed chemical laser can be followed. The main difference between the model discussed here and the ones found in the literature for HF laser only, is that the handling the rotational distribution.

The great advantages of this model are in reducing the computational efforts in performing simulation without affecting the reliability of the results. Instead of dealing with thirty or more differential equations (one equation for each rotational state) per vibration one has to deal with few equations only. This can reduce the total number of equations in a model which follows the development in time of radiation from each vibrational state separately. As a final point to refer to the preliminary study of $\mathrm{HCl}$ laser. Although no detailed study has been performed it is my belief that the result is acceptable in comparison with the available HF chemical laser results.

\section{REFERENCES:}

1- Basov, N.G., Bashkin, A.S., Igoshin, V.L.,Oraevsky, A.N., and Shcheglov, V.A., (1990):Chemical Laser, (Springer Verlag).

2- Bravy, B.G., Vasiliev, G.K., Kiriyanov, V.L., Makarov, E.F., and Chernyshev, Yu.A., (1996): Pulsed Chemical Hydrogen Fluoride Laser Problems, Developments, and Applications, BRAS Physics/Supplement Phys. Vibrat. 60:117.

3- Das, P., (1991): Laser and Optical Engineering, (Springer Verlag).

4- Detweiler, G. L., Sentman, L. H., and Carroll, D. L.,(2005): The Possibility of Hot Reaction Enhancement of $\mathrm{CW}$ HF Laser Performance, $36^{\text {th }}$ AIAA Plasmadynamics and Laser Conference. pp(1-14).
5- Eletskii, A.V.,(1981): Processes ion Chemical Laser, Phys. Usp. 24:475.

6- Emanual, G., (1971): Analytical Model for a Continuous Chemical Laser, J. Quant. Spect. Radiat. Trans. 11:1481.

7- Gordon, E.B., Matyushenko, V.I., and Sizov, V.D.,(1997): High Efficient Multi-Frequency Pulsed Chemical Laser on $\mathrm{HCl}$ and $\mathrm{HF}$ Vibration Transitions. Appl. Energy : Rus. J. Fuel, Power and Heat systems 35:81.

8- Kasper, J.V.V, and Pimentel, G.C., (1965): HCl Chemical Laser, Phys. Rev. Lett. 14:352.

9- Kerber, R.L., and Whittier, J.S., (1976): Chain Reaction Pulsed HF Laser: a simple model, Appl. Opt. 15:2358.

10-Palekar, A., (2004): Hydrodynamics Inside A Chemical Laser, Internet. $\mathrm{pp}(1-15)$.

11-Stitch, M.L., (1979), Laser Hand Book, (North-Holland, Amsterdam).

12-Wisniewski, C. F. (2003) : Spatially Resolved Sub-doppler Overtone Gain Measurements in a Small Scale Supersonic HF Laser. PhD thesis, University of New Mexico. 


\section{مقارنة بعض معلمات ليزر فلوريد الهايدروجين (HF)

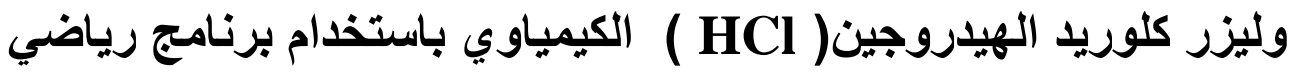

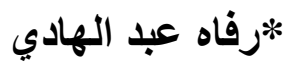

*قنم الفيزياء/كلية العلوم للبنات/جامعة بغداد

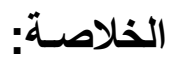

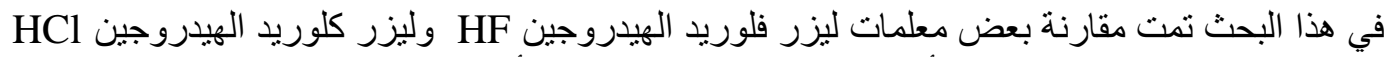

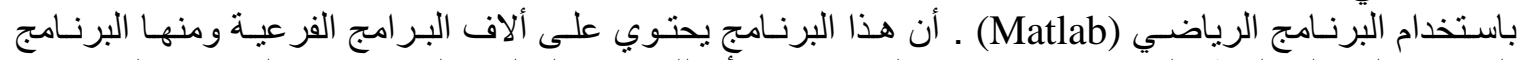

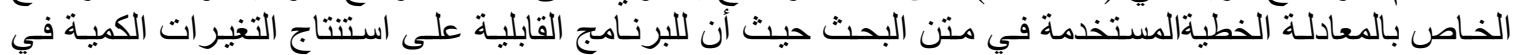

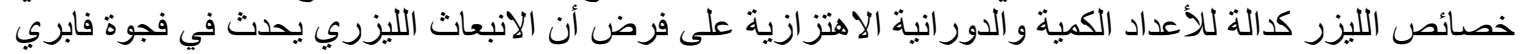

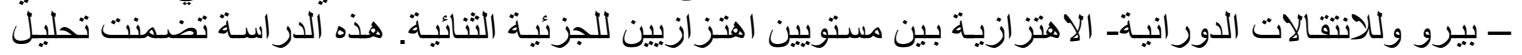

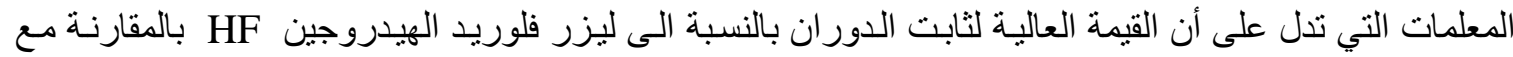

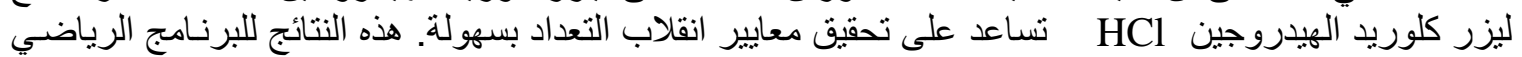

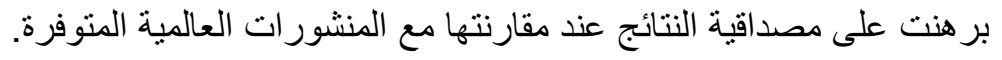

